\title{
Análise multitemporal de parte da Reserva do Alto Rio Guamá, Paragominas, PA
}

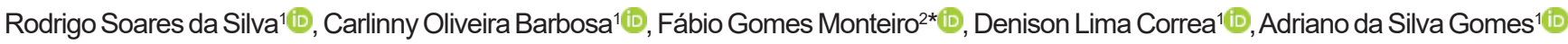 \\ 1 Universidade Federal Rural da Amazônia, PA-256, s/n, Nova Conquista, CEP 68625-970, Paragominas, PA, Brasil \\ ${ }^{2}$ Universidade Estadual do Centro-Oeste, PR 153, Km 7, CEP 84500-000, Irati, PR, Brasil
}

*Autor correspondente:

fabiogomesmonteiro2035@gmail.com

Termos para indexação:

Índice de vegetação

Imagens de satélite

Conservação da natureza

Index terms:

Vegetation index

Satellite imagery

Nature conservation

Histórico do artigo:

Recebido em 18/08/2018

Aceito em 22/02/2019

Publicado em 04/07/2019

doi: 10.4336/2019.pfb.39e201801712

\section{(c) $(\$)$}

Resumo - O objetivo dessa pesquisa foi verificar mudanças na cobertura vegetal de parte da Reserva do Alto Rio Guamá em Paragominas, PA, por meio de índices de vegetação, visando elaborar um panorama multitemporal da degradação ambiental. As imagens foram obtidas da base do INPE e a aquisição de bases vetoriais na base do IBGE. O processamento de imagens foi realizado com o programa ENVI 4.7, onde se utilizou as bandas R5, G4 e B3 para as imagens de 1991 e 2010 e as bandas 6R, 5G e 4B para a imagem de 2016. Foi realizada a reprojeção, recorte por máscara e retificação geométrica por pontos de controle. A classificação do índice de vegetação por diferença normalizada (NDVI) considerou as classes água, sem vegetação, gramíneas, capoeira, floresta secundária e floresta densa, para gerar os índices por área (ha). No intervalo de aproximadamente 25 anos houve redução da cobertura florestal, possivelmente pela expansão de atividades agropecuárias e extração de madeira.

\section{Multitemporal analysis of the Upper Rio Guamá Reserve, Paragominas, PA}

\begin{abstract}
The objective of the research was to verify changes in vegetation cover of part of the Upper Rio Guamá Reserve in Paragominas, Para State, Brazil, through vegetation indexes, aiming at a multitemporal overview of environmental degradation. The images were obtained from INPE databases and the vector bases acquisition from IBGE. Image processing was performed using ENVI 4.7 software, where the bands R5, G4 and B3 were used for the images of 1991 and 2010 and the bands 6R, 5G and 4B for the image of 2016. We also performed re-projection, mask cutting and geometric rectification by control points. The classification of normalized difference vegetation index (NDVI) was made for water, no vegetation, grass, capoeira (early forest regeneration after the abandonment of agricultural practices), secondary forest and dense forest classes, to generate the area indices (ha). . In 25 years there were considerable changes in forest cover, probably due to agriculture expansion and timber extraction activities.
\end{abstract}

Trabalho apresentado no V Seminário de Atualização Florestal, 24 e 28 de setembro de 2018, Irati, PR. 


\section{Introdução}

A presença de florestas, se constitui em importante indicador de qualidade ambiental. É responsável por várias funções, como purificação do ar, distribuição de oxigênio, manutenção e recarga hídrica, fornecimento de matéria orgânica para os solos e de matéria-prima necessárias para a realização de diversas atividades antrópicas. Dada a sua importância, se faz necessário seu mapeamento e monitoramento com relação às respostas aos elementos ambientais naturais e sociais, sendo alguns deles possíveis de serem analisados por meio de imagens de satélites (Barbosa \& Dorigon, 2014).

Por meio do monitoramento de imagens verificam-se mudanças ao longo do tempo das condições ambientais em função das atividades humanas, possibilitando manter o controle permanente de modificações ambientais. A utilização de ferramentas de geotecnologias é de extrema valia na avaliação e monitoramento ambiental, pois fornecem informações rápidas, facilitam a aquisição e manipulação de dados de alvos de difícil acesso, repetitividade, além da possibilidade de constante atualização de informações de áreas, principalmente daquelas consideradas sensíveis à ação do homem (Azevedo \& Mangabeira, 2001).

$\mathrm{Na}$ literatura são encontrados estudos que utilizam técnicas e métodos de processamento de dados de sensoriamento remoto da vegetação para estudo dos ecossistemas, podendo-se citar Santos Júnior \& Fernandes (2014), Silva Neto (2013) e Vieira et al. (2018). Esses estudos auxiliam no controle das mudanças na paisagem, onde os índices de vegetação vêm sendo empregados para detectar alterações no uso do solo, bem como para estabelecer modelos biofísicos associados à condição da vegetação, exercendo importante função para o equilíbrio da biota (Tundisi \& MatsumuraTundisi, 2010).

Apesar de observarmos na literatura científica as potenciais aplicações e limitações de mais de 50 índices de vegetação, os dois mais comumente utilizados são: razão simples (RVI) e o índice de vegetação por diferença normalizada (NDVI) (Moreira, 2003). O processamento digital de imagens é fonte para obtenção do NDVI, onde os índices da vegetação são modelos que resultam da combinação de refletância nas bandas do vermelho e do infravermelho próximo (Moreira, 2000). Rouse et al. (1974) normalizaram a razão simples para o intervalo de -1 a +1 . Em alvos terrestres, os limites inferior e superior aproximadamente, 0 e 0,80 respecitavmente, sendo também utilizado como parâmetro para indicar a mudança vegetal no vigor das plantas (Pozoni \& Shimabukuro, 2007). Além disso, o NDVI é importante porque a razão reduz muitas formas de ruídos que em alguns casos são apresentados nas imagens. Sendo essa o motivo desse índice de vegetação mais utilizado (Hentz et al., 2014).

O desmatamento na Amazônia brasileira tem atraído a atenção de pesquisadores e do poder público, em suas diversas esferas, em torno de medidas e políticas que envolvem sua aferição como controle (Peres et al., 2010). No Pará, a interferência humana sob as áreas florestadas é um indício de um agravante da degradação ambiental, principalmente onde há Unidades de Conservação Ambiental para proteção da fauna, flora, microrganismos, paisagens, e todos os processos ecológicos pertinentes aos ecossistemas naturais (Henry, 2005). As UCs protegem também o patrimônio históricocultural, as práticas e o modo de vida das populações tradicionais, permitindo o uso sustentável dos recursos naturais (Olivato \& Gallo Junior, 2008).

Salles et al. (1998) afirmam que para proporcionar a sustentabilidade em terras indígenas deve-se fazer uma análise do meio físico para avaliação do uso e ocupação do solo por meio do monitoramento, identificando os processos de degradação. Segundo Brígida (2004) a intrusão (invasão de não índios) e os desmatamentos crescentes vêm comprometendo a sobrevivência dos Tembé, interferindo negativamente no seu universo cultural, gerando conflitos entre instituições, agentes políticos locais, índios e agricultores, expropriando gradativamente seu território. $\mathrm{O}$ estudo da densidade da cobertura vegetal e sua espacialidade é um mecanismo relevante para análises voltadas à degradação ambiental, gestão e planejamento dos recursos naturais. Neste contexto, o objetivo deste trabalho foi verificar mudanças na cobertura vegetal de parte da Reserva do Alto Rio Guamá em Paragominas, PA, por meio de índices de vegetação, visando elaborar um panorama multitemporal da degradação ambiental.

\section{Material e métodos}

\section{Área de estudo}

A Reserva do Alto Rio Guamá (Figura 1), está situada entre os paralelos $01^{\circ} 40^{\prime} \mathrm{S}$ e $03^{\circ} 00^{\prime} \mathrm{S}$ e os meridianos 
$46^{\circ} 20^{\prime} \mathrm{W}$ e $47^{\circ} 10^{\prime} \mathrm{W}$, com uma superfície de 279.000 ha, ocupando um trecho compreendido entre o Rio Guamá (margem direita) e o Rio Gurupi (margem esquerda).

O clima é do tipo Awi e Ami, sendo que o primeiro predomina (cerca de $80 \%$ ), ou seja, vigora o tropical quente e úmido, com precipitações cuja distribuição no decurso do ano não apresenta nenhum mês com menos de $60 \mathrm{~mm}$. O tipo Ami, tem características de tropical úmido de moção, com precipitação anual excessiva e em alguns meses com precipitações inferiores a $60 \mathrm{~mm}$, o que compreende a maior parte da Amazônia (Projeto..., 2000). A temperatura média anual é de $26,9^{\circ} \mathrm{C}$ e precipitação anual de $2.449 \mathrm{~mm}$. O solo predominante é Latossolo Amarelo (56\%), correspondendo a uma superfície de 156.440,20 ha, (Sales, 1999).
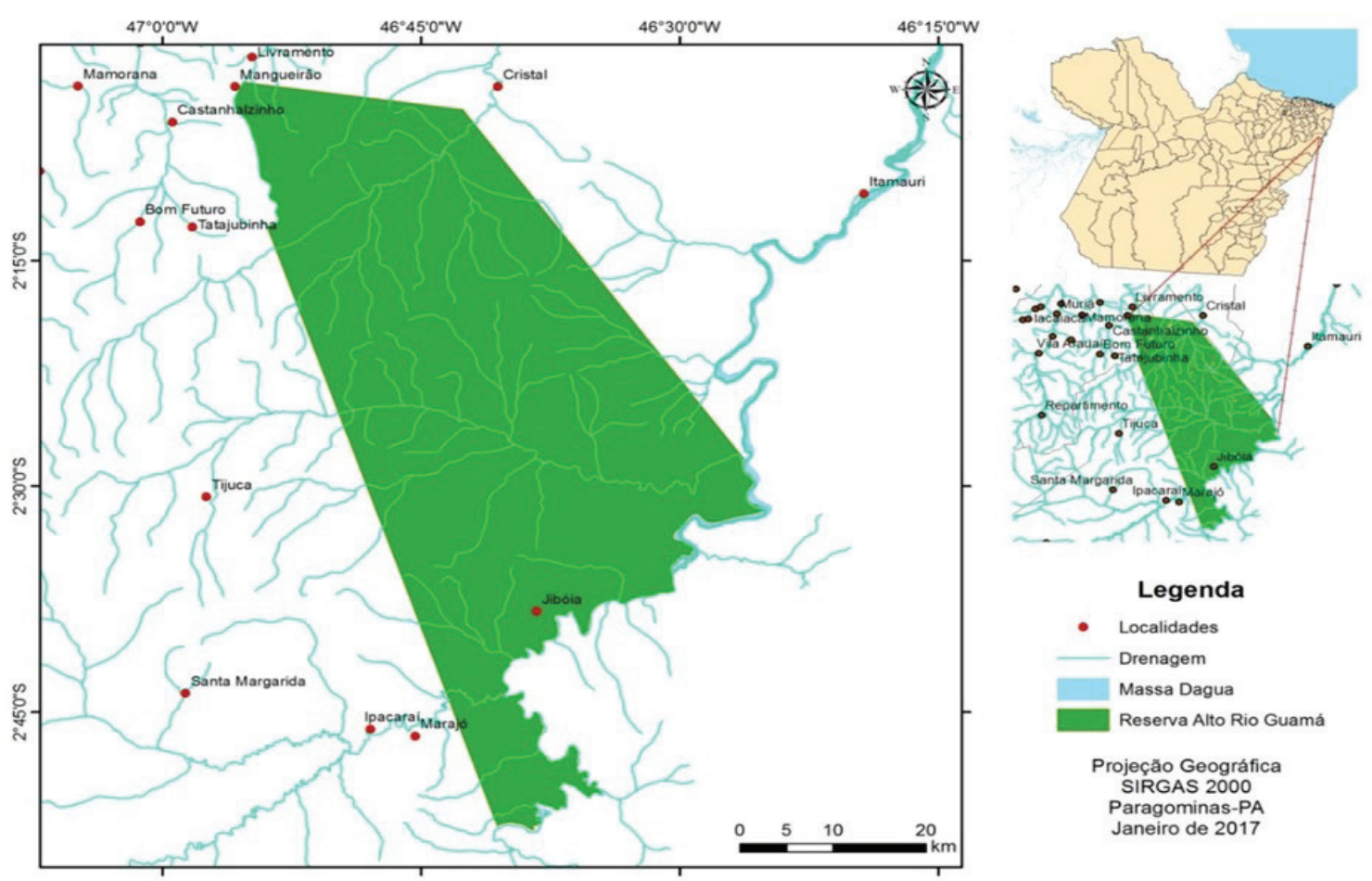

Figura 1. Mapa de localização de parte da Reserva do Alto Rio Guamá, município de Paragominas, estado do Pará, Brasil.

Figure 1. Location map of part of the Upper Rio Guamá Reserve, Paragominas municipality, state of Pará, Brazil.

\section{Processamento das imagens}

O mapeamento de vegetação na Reserva do Alto Rio Guamá foi realizado com imagens dos satélites LandSat 5 sensor TM e LandSat 8 sensor OLI, conforme as referências de data e órbita-ponto (Tabela 1). Foram utilizadas apenas as imagens de 1991, 2010 e 2016, por serem as mais atuais e com baixa presença de nuvens, possibilitando uma melhor classificação.

As imagens foram obtidas da base disponibilizada pelo Instituto Nacional de Pesquisas Espaciais (INPE) e pela base do Serviço Geológico dos Estados Unidos (USGS). A aquisição de bases vetoriais foi feita da base disponibilizada pelo banco de dados Instituto Brasileiro de Geografia e Estatística (IBGE). Foi criado um banco de dados com informações espaciais, com limite do município, estradas, localidades, massa d'água, drenagem e limite da Reserva do Alto Rio Guamá.

O processamento de imagens foi realizado com o programa ENVI 4.7, utilizando as bandas R5, G4 e B3 do Landsat 5 sensor TM e as bandas R6, G5 e B4 do Landsat 8 sensor OLI. Foi feito o recorte por 
máscara, sendo a referência o limite da Reserva Alto Rio Guamá. Precedendo a elaboração do mosaico, foi feita a correção geométrica, com o intuito de minimizar os efeitos atmosféricos na radiância e deixar os dados multitemporais na mesma escala radiométrica. Assim, a imagem foi reprojetada para o sistema Universal Transversa de Mercator (UTM) zona $23 \mathrm{M}$ e feita a retificação geométrica com 22 pontos de controle e erro médio quadrático de 0,2246 .

Tabela 1. Características das imagens da área de estudo, município de Paragominas, estado do Pará, Brasil.

Table 1. Images characteristics of the study area, Paragominas municipality, state of Pará, Brazil.

\begin{tabular}{ccccc}
\hline Data & $\begin{array}{c}\text { Sensor/ } \\
\text { Satélite }\end{array}$ & Bandas & $\begin{array}{c}\text { Resolução } \\
\text { espacial }\end{array}$ & $\begin{array}{c}\text { Órbita/ } \\
\text { Ponto }\end{array}$ \\
\hline $\mathbf{2 4 / 0 7 / 1 9 9 1}$ & TM/Landsat 5 & $5 \mathrm{R}, 4 \mathrm{G}$ e 3B & $30 \mathrm{~m}$ & $222 / 62$ \\
& & & & \\
$\mathbf{2 6 / 0 6 / 2 0 1 0}$ & $T M /$ Landsat 5 & $5 \mathrm{R}, 4 \mathrm{G}$ e 3B & $30 \mathrm{~m}$ & $222 / 62$ \\
$\mathbf{2 0 / 0 5 / 2 0 1 6}$ & OLI/Landsat 8 & $6 \mathrm{R}, 5 \mathrm{G}$ e 4B & $30 \mathrm{~m}$ & $222 / 62$ \\
\hline
\end{tabular}

As imagens adquiridas foram importadas para o programa ArcGis 10.1, onde foi criado um banco de dados. Posteriormente, foram gerados planos de informação pertencentes à categoria imagem, para onde foram importadas as imagens "tif". O mosaico foi elaborado para apenas uma parte da Reserva, por não haver ponto/órbita disponível na data de passagem para a outra cena.

O cálculo adequado dos índices de vegetação demanda a conversão dos valores de DN para valores físicos, como radiância e reflectância (Ponzoni \& Shimabukuro, 2009). Assim, a conversão pixel a pixel para radiância bidirecional aparente foi realizada segundo Markham \& Baker (1986), utilizando a equação 1.

$$
L_{0}(»)=a_{i}+\frac{b_{i}-a_{i}}{255} \cdot D N
$$

Onde: $a$ e $b=$ radiâncias mínimas e máximas ( $\mathrm{W} \mathrm{m}^{-2} \mathrm{sr}^{-1}$ $\mathrm{m}^{-1}$ ) detectadas pelo sensor; $\mathrm{TM}$ e $\mathrm{DN}=$ números digitais da imagem ( 0 a 255) e, $i=$ bandas do satélite em estudo.

A equação 2 foi utilizada para determinação do índice de vegetação da diferença normalizada (NDVI), conforme Rouse et al. (1974), visando mapear, determinar a quantidade de vegetação e analisar a condição da cobertura vegetal.

$$
N D V I=\frac{N I R-R E D}{N I R+R E D}
$$

Onde: NDVI = índice de vegetação da diferença normalizada; RED e NIR = bandas do vermelho e do infravermelho próximo, respectivamente.

\section{Classes utilizadas}

As classes de uso do solo foram mapeadas de acordo com a Resolução nº 28 de 7 de dezembro de 1994 (Brasil, 1994) e com o manual técnico da vegetação brasileira (IBGE, 2012). Para classificação supervisionada pelos índices de NDVI, foram utilizadas informações da escala de índices presentes no intervalo de -1 a 1 , onde foi possível observar as classes por meio da técnica de fotogrametria, analisando-se textura, cor e informações de reconhecimento espectral para classificação (Tabela 2).

Tabela 2. Determinação das classes por intervalos do índice de vegetação da diferença normalizada (NDVI).

Table 2. Determination of classes by normalized difference vegetation index (NDVI) intervals.

\begin{tabular}{cc}
\hline Classes & Intervalos \\
\hline Água & -1 a $-0,75$ \\
Sem vegetação & $-0,75$ a $-0,25$ \\
Gramíneas & $-0,25$ a 0,25 \\
Capoeira & 0,25 a 0,50 \\
Floresta secundária & 0,50 a 0,75 \\
Floresta densa & 0,75 a 1 \\
\hline
\end{tabular}

Os valores gerados pelo NDVI foram processados em planilha eletrônica, para o estabelecimento de relação entre as classes formadas e análise dos mapas de diferenças entre classes nos anos 1991, 2010 e 2016 . Os histogramas foram gerados por meio da análise estatística, onde foi possível utilizar o método do desvio quadrático que apresenta a melhor uniformidade dos dados.

\section{Resultados}

As áreas calculadas para as diferentes das classes definidas pelos intervalos do índice de vegetação da diferença normalizada (NDVI) nos anos 1991, 2010 e 2016 estão apresentadas na Tabela 3. 
Tabela 3. Área das classes definidas pelos intervalos do índice de vegetação da diferença normalizada (NDVI) em 1991, 2010 e 2016, município de Paragominas, PA.

Table 3. Area of classes defined by data obtained by normalized difference vegetation index (NDVI) in 1991, 2010 and 2016 , Paragominas municipality, Pará State, Brazil.

\begin{tabular}{cccccccc}
\hline & & \multicolumn{5}{c}{ Área (ha) } \\
\cline { 3 - 7 } Classes & Intervalos & $\mathbf{1 9 9 1}$ & $\mathbf{\%}$ & $\mathbf{2 0 1 0}$ & $\mathbf{\%}$ & $\mathbf{2 0 1 6}$ \\
\hline Água & $-1,00$ a $-0,75$ & $6.630,50$ & 2,89 & $10.356,04$ & 4,51 & $2.106,64$ & 0,92 \\
Sem vegetação & $-0,75$ a $-0,25$ & $8.333,80$ & 3,63 & $15.812,98$ & 6,89 & $2.986,35$ & 1,30 \\
Gramíneas & $-0,25$ a 0,25 & $15.610,58$ & 6,80 & $28.973,60$ & 12,62 & $6.831,65$ & 2,98 \\
Capoeira & 0,25 a 0,50 & $56.037,80$ & 24,41 & $54.450,02$ & 23,72 & $12.192,16$ & 5,31 \\
Floresta secundária & 0,50 a 0,75 & $56.837,78$ & 24,76 & $73.198,70$ & 31,88 & $70.400,91$ & 30,66 \\
Floresta densa & 0,75 a 1,00 & $86.137,57$ & 37,52 & $46.796,70$ & 20,38 & $135.070,33$ & 58,83 \\
\hline Total & & 229.588 & 100 & 229.588 & 100 & 229.588 \\
\hline
\end{tabular}

As áreas das classes água, sem vegetação e gramíneas aumentaram entre os anos de 1991 e 2010, porém no intervalo de 2010 a 2016 essas áreas diminuíram de forma considerável. Ao analisar a classe capoeira, observa-se que houve diminuição entre 2010 e 2016 (Figura 2). As classes floresta secundária e floresta densa tiveram suas áreas de cobertura alteradas em um intervalo de aproximadamente 25 anos.

Observou-se em 1991 uma melhor distribuição dos valores dentro das classes estudadas (Figura 3), o que indica que os valores do NDVI estão distribuídos principalmente entre os valores 0,00 e 0,50 (média $=0,32$ e desvio padrão $=0,25$ ).

A distribuição de valores do NDVI em 2010 oscilaram de -1 a 0,67 (Figura 4), distribuídos, principalmente, entre $-0,50$ e 0,67 . Nesse ano a concentração da vegetação foi nas classes gramíneas, capoeira e floresta secundária (média $=0,18$ e desvio padrão $=0,31$ ).

A distribuição de valores de NDVI em 2016 oscilaram entre 0,60 e 0,92 (Figura 5) com média $=0,76$ e desvio padrão $=0,20$. O histograma apresenta curva pontiaguda em relação à curva normal, o que indica que os valores de NDVI estão concentrados nas classes floresta secundária e floresta densa.

As transformações das paisagens apresentadas nos mapas (Figura 6) estão expressas pela coloração em azul, vermelho, amarelo e verde, onde a escala próxima do valor -1 indica ausência da vegetação e próximo a 1 indica quantidade de cobertura florestal e presença de indivíduos de grande porte e áreas foliares.

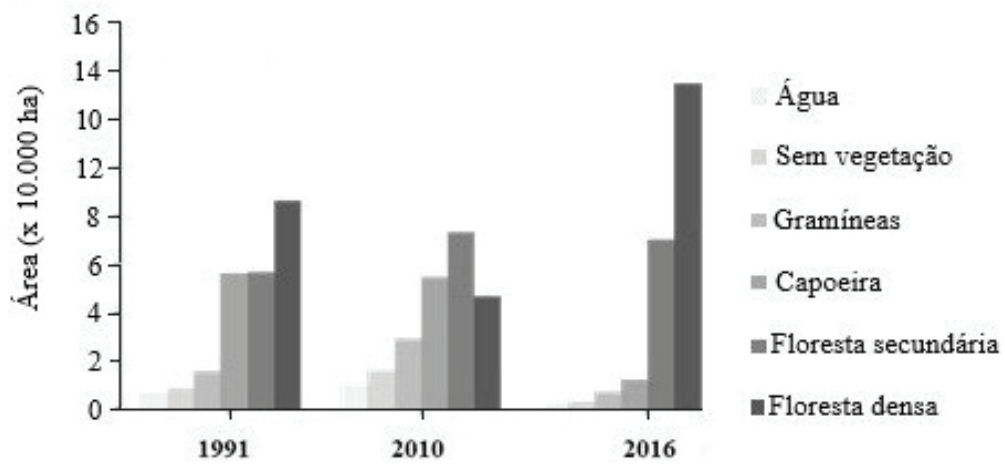

Figura 2. Área das classes de uso do solo em parte da Reserva do Alto Rio Guamá em 1991, 2010 e 2016, município de Paragominas, PA.

Figure 2. Area of soil use classes of part of Alto Rio Guamá Reserve in 1991, 2010 and 2016, Paragominas municipality, Pará state, Brazil. 
Figura 3. Distribuição estatística dos índices de vegetação da diferença normalizada (NDVI) referente a 1991 de parte da Reserva Alto Rio Guamá, município de Paragominas, PA.

Figure 3. Statistical distribution of normalized difference vegetation index (NDVI) from 1991 of part of Alto Rio Guamá Reserve, Paragominas municipality, Pará state, Brazil.

Figura 4. Distribuição estatística dos índices de vegetação da diferença normalizada (NDVI) referente a 2010 de parte da Reserva Alto Rio Guamá, município de Paragominas, PA.

Figure 4. Statistical distribution of normalized difference vegetation index (NDVI) from 2010 of part of Alto Rio Guamá Reserve, Paragominas municipality, Pará state, Brazil.

Figura 5. Distribuição estatística dos índices de vegetação da diferença normalizada (NDVI) referente a 2016 de parte da Reserva Alto Rio Guamá, município de Paragominas, PA.

Figure 5. Statistical distribution of normalized difference vegetation index (NDVI) from 2016 of part of Alto Rio Guamá Reserve, Paragominas municipality, Pará state, Brazil.
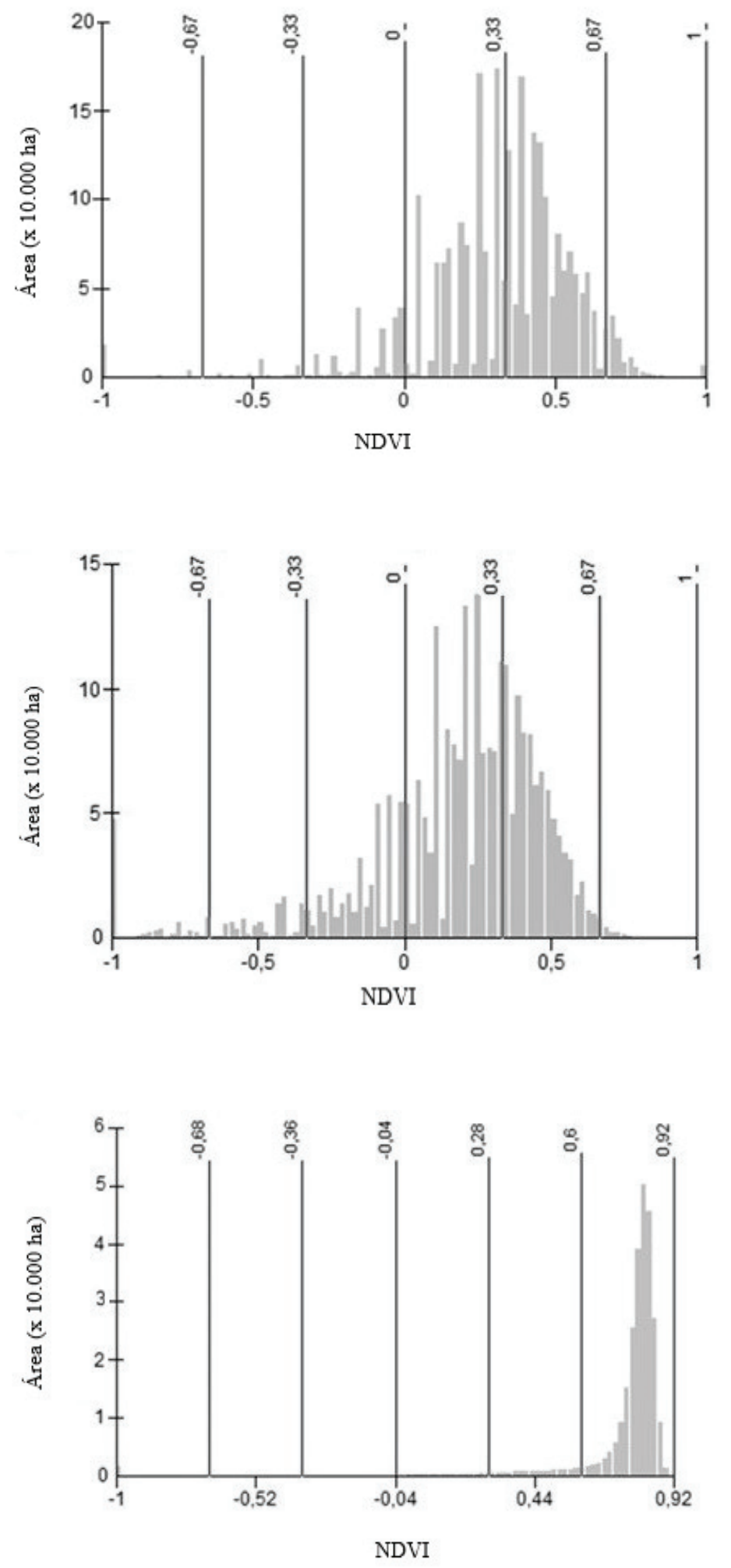
Figura 6. Índices de vegetação por diferença normalizada (NDVI) de 1991 (A), 2010 (B) e 2016 (C) de parte da Reserva do Alto Rio Guamá, município de Paragominas, PA.

Figure 6. Map of vegetation indexes by normalized difference (NDVI) of 1991 (A), 2010 (B) and 2016 (C) from part of the Alto Rio Guamá Reserve, Paragominas municipality, Pará State, Brazil.
A

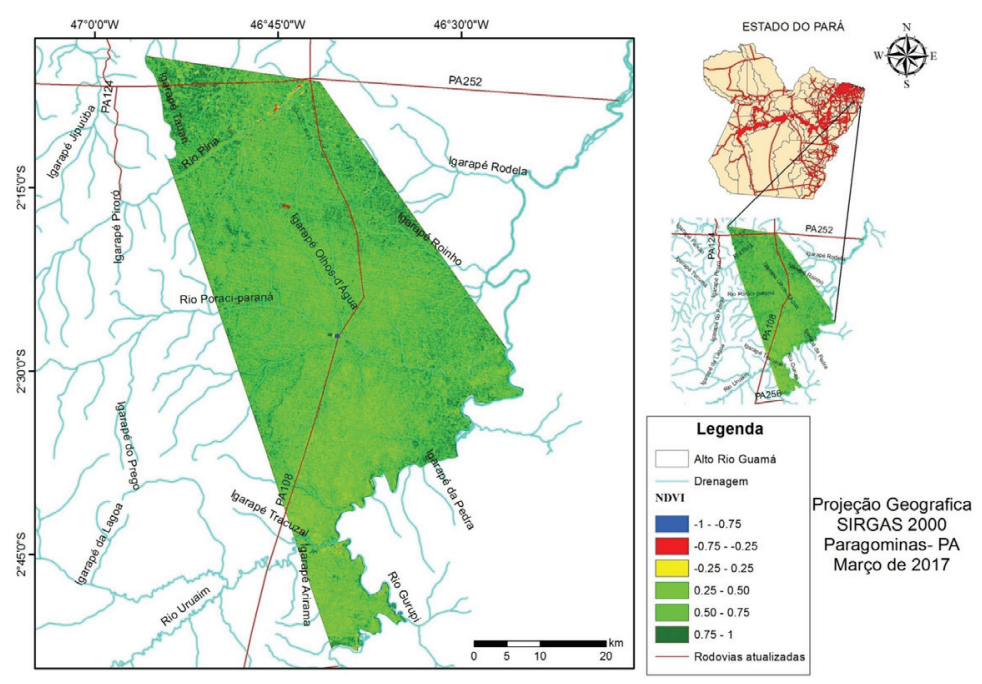

B
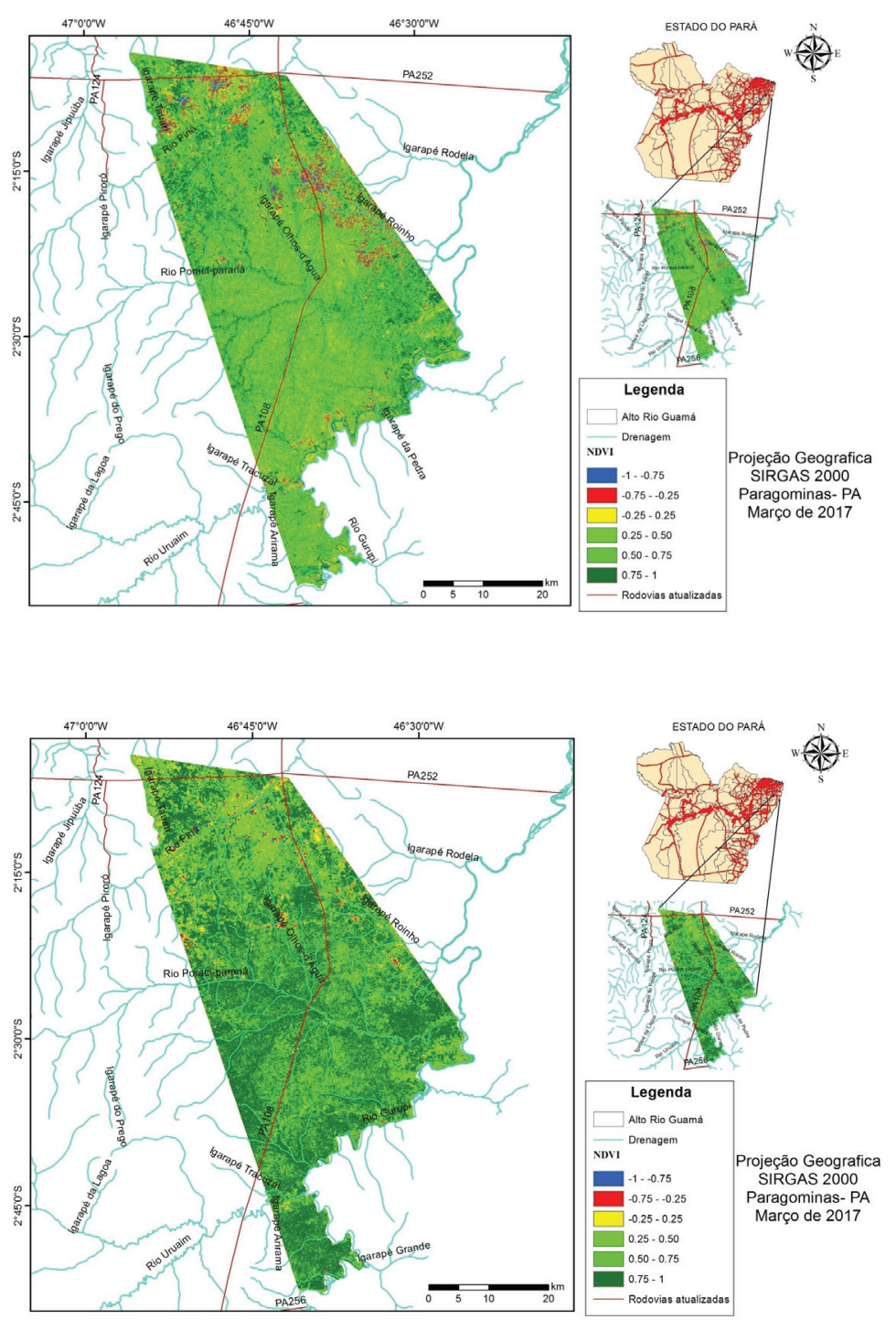


\section{Discussão}

Ao avaliar pastagens em terras indígenas, Pinhati (2005) constatou que, embora os ocupantes não-índios tenham saído a dez anos da área, não houve recuperação da vegetação nativa. Era esperado ocupação mais rápida da área por plantas de porte arbustivo, seguindo a sucessão natural dos ecossistemas. Essas informações não corroboram com a presente pesquisa, uma vez que as classes sem vegetação e gramíneas diminuíram no intervalo de 2010 a 2016 (Tabela 3). Isso sugere que o abandono das áreas sem vegetação por seis anos resultou na formação de áreas florestais, devido ao processo de regeneração natural. Outro fator que contribuiu para a redução de áreas sem vegetação foram políticas públicas aplicadas, como o Arco de Fogo que ocorreu no município de Paragominas em 2008, região fiscalizada onde ocorria a exploração ilegal de madeira.

Com a ausência de ações efetivas de gestão e com os atuais padrões de uso dos recursos naturais nas áreas de entorno, diversas Unidades de Conservação e terras indígenas têm sofrido grande pressão de atividades ilegais. Brígida (2004) relatou em sua pesquisa que madeireiros ilegais e grileiros se voltaram para um mosaico de áreas protegidas contíguas (Awá, Alto Rio Guamá, Alto Turiaçu e Caru, bem como a Reserva Biológica Gurupi). Essas áreas incluem terras indígenas protegidas por lei, no entanto, quase um terço dos territórios Alto Rio Guamá e Awá foram destruídos pela extração ilegal de madeira entre 1986 e 2011. A autora ainda menciona que os madeireiros descumprem flagrantemente a lei, entrando com frequência e armados, para retirar cargas de madeira da área.

Os Tembé têm sido obrigados a conviver com centenas de famílias de posseiros em suas terras e sofrem os efeitos da atuação criminosa de madeireiros, fazendeiros e empresários (Brígida, 2004). Desta forma, faz-se necessário avaliar essas áreas, impedindo o uso ilegal dos recursos naturais, para garantir o direito dos índios à terra, assegurar a proteção dos limites demarcados e impedir a ocupação por terceiros, preservando os recursos ambientais necessários ao seu bem-estar e à sua integridade física e cultural, segundo seus usos, costumes e tradições (Brasil, 1988). Portanto, as áreas protegidas e terras indígenas devem manter-se como um componente central das políticas públicas, para favorecer a conservação dos recursos naturais e a mitigação dos impactos ambientais ocasionados pelo desmatamento na Amazônia brasileira (Arima et al, 2007; Fearnside, 2008). Além disso, as áreas protegidas restringem o desmatamento, e a manutenção da vegetação, sendo eficiente como mitigadora das mudanças climáticas, visto que essas áreas reduzem o efeito estufa (Fearnside, 2008; Soares-Filho et al, 2010).

Nunes (2010), avaliando a efetividade das Unidades de Conservação e das terras indígenas na contenção do desflorestamento na Amazônia Legal, constatou em seu estudo que uma provável causa das terras indígenas serem pouco desflorestadas é a proteção ativa realizada pelas comunidades indígenas, as quais, com algumas exceções, têm relações com o seu entorno, e que $1 \%$ de desmatamento dessas áreas pode ser consequência da não conclusão de processos demarcatórios que acaba deixando essas áreas vulneráveis às invasões e às explorações ilegais.

Houve redução de área de capoeira entre 2010 e 2016 (Figura 2). Isso se deve pela prática agrícola ser a principal atividade das aldeias que existem na reserva, principalmente para o cultivo de mandioca, onde se faz necessário a limpeza de áreas de capoeira que após a colheita da cultura ficam em pousio até que passe o período e seja realizado novo plantio.

A cobertura das classes floresta secundária e floresta densa foram alteradas, considerando o intervalo de aproximadamente 25 anos (Figura 6). Apesar de existirem políticas públicas de meio ambiente que proíbem a retirada de madeira nestas áreas, e mesmo tendo retrocedido a taxa de desmatamento, este processo ainda ocorre, sendo a extração de madeira de alto valor comercial responsável por parte das mudanças de uso da terra na Amazônia, interferindo na composição e paisagem florestal, com perda da diversidade de espécies e de carbono florestal (Instituto Nacional de Pesquisas Espaciais, 2008; Soares \& Mota, 2010).

\section{Conclusões}

A aplicação do índice de vegetação por diferença normalizada (NDVI) possibilitou a análise e interpretação das imagens referentes ao intervalo de aproximadamente 25 anos em parte da Reserva do Alto Rio Guamá, município de Paragominas, PA, indicando alterações na incidência da cobertura vegetal devido à expansão de atividades de agricultura e extração de madeira.

Constatou-se que ainda há extração de madeira na área em estudo, porém de forma localizada e em 
pontos estratégicos. Novos estudos são necessários para subsidiar a elaboração de políticas públicas para a caracterização e quantificação das perdas e ganhos de nas diferentes classes de cobertura vegetal.

\section{Referências}

Arima, E. Y. et al. Fire in the Brazilian amazon: a spatially explicit model for policy impact analysis. Journal of Regional Science, v. 47, p. 541-567, 2007.

Azevedo, E. C. de \& Mangabeira, J. A. de C. Mapeamento de uso das terras utilizando processamento digital de imagem de sensoriamento remoto. Campinas: Embrapa Monitoramento por Satélite, 2001. 16 p. (Embrapa Monitoramento por Satélite. Comunicado técnico, 6).

Barbosa, L. G. \& Dorigon, L. P. Análise temporal da cobertura vegetal no município de Teresina/PI a partir da aplicação de NDVI. In: CONGRESSO BRASILEIRO DE CARTOGRAFIA, 26.; CONGRESSO BRASILEIRO DE GEOPROCESSAMENTO, 5.; ESPOSICARTA, 25., 2014. Gramado. Mapas conectando o Brasil e a América do Sul: anais. Rio de Janeiro: Sociedade Brasileira de Cartografia, Geodésia, Fotogrametria e Sensoriamento Remoto, 2014. Disponível em: < http://www.cartografia.org.br $>$. Acesso em: 20 mar. 2018.

Brasil. Constituição da República Federativa do Brasil: texto constitucional promulgado em 5 de outubro de 1988, com as alterações determinadas pelas Emendas Constitucionais de Revisão nos 1 a 6/94, pelas Emendas Constitucionais nos 1/92 a 91/2016 e pelo Decreto Legislativo no 186/2008. Brasília, DF: Senado Federal, Coordenação de Edições Técnicas, 2016. 496 p.

Brasil. Resolução CONAMA no ${ }^{\circ 2}$, de 7 de dezembro de 1994. Definição da vegetação primária e secundária nos estágios inicial, médio e avançado. Disponível em: <http://www.ciflorestas.com. br/arquivos/lei_resolucao_281994_11138.pdf $>$. Acesso em: $20 \mathrm{de}$ jul. de 2018 .

Brígida, M. R. S. S. Sistema de produção agrícola familiar do posto indígena Alto Rio Guamá-Povo Tembé. Revista Agricultura Familiar: Pesquisa, Formação e Desenvolvimento, v. 4, n. 4, p. 231-258, 2004.

Fearnside, P. M. Mudanças climáticas e conservação na Amazônia Brasileira. In: CONGRESSO NACIONAL DE BOTÂNICA, 59.; REUNIÃO NORDESTINA DE BOTÂNICA, 31; CONGRESSO LATINO AMERICANO Y DEL CARIBE DE CACTÁCEAS Y OTRAS SUCULENTAS, 4.; CONGRESS OF INTERNATIONAL ORGANIZATION FOR SUCULENT PLANT STUDY, 30., 2008, Natal. Atualidades, desafios e perspectivas da botânica no Brasil: anais. Natal: UFERSA: UFRN: SBB, 2008. p. 247-150.

Henry, G. G. S. A Importância das Unidades de Conservação na preservação da diversidade biológica. Revista LOGOS, n. 12, 2005.

Hentz, A. M. K. et al. Técnicas de sensoriamento remoto para estimativa de Biomassa em ambientes florestais. Enciclopédia Biosfera, v.10, n. 18, p. 2810-2823, 2014.
IBGE. Instituto Brasileiro de Geografia e Estatística. Manual técnico da vegetação brasileira. 2. ed. Rio de Janeiro, 2012. Disponível em: $<$ https://biblioteca.ibge.gov.br/visualizacao/livros/liv63011.pdf $>$. Acesso em: 20 jul. 2018.

Instituto Nacional de Pesquisas Espaciais. Disponível em: < http:// www.inpe.br/ > . Acesso em: 11 jul. 2018.

Instituto Nacional de Pesquisas Espaciais. Coordenação Geral de Observação da Terra. Monitoramento da cobertura florestal da Amazônia por satélites sistemas Prodes, Deter, Degrad e Queimadas 2007-2008. São José dos Campos, 2008. Disponível em: <http://www.obt.inpe.br/prodes/Relatorio_Prodes2008.pdf> Acesso em: 28 ago. 2018.

Markham, B. L. \& Barker, J. L. Landsat MSS and TM postcalibration dynamic ranges, exoatmosphericreflectances and at-satellite temperatures. [S.1.]: NASA/Goddard Space Flight Center Greenbelt, 1987. (MD, 20771).

Moreira, R. C. Influência do posicionamento e da largura de bandas de sensores remotos e dos efeitos atmosféricos na determinação de índices de vegetação. 2000. 181 f. Dissertação (Mestrado) - Instituto Nacional de Pesquisas Espaciais, São José dos Campos.

Moreira, M. A. Fundamentos de sensoriamento remoto e metodologias de aplicação. 2. ed.Viçosa: UFV, 2003. 307 p.

Nunes, T. do S. S. A efetividade das Unidades de Conservação e das Terras Indígenas na contenção do desflorestamento na Amazônia Legal. 2010. 77 f. Dissertação (Mestrado em Ciências Ambientais) - Universidade Federal do Pará, Museu Paraense Emilio Goeldi, Belém.

Olivato, D. \& Gallo Junior, H. Unidades de conservação: conservando a vida, os bens e os serviços ambientais. São Paulo, 2008.

Peres, C. A. et al. Biodiversity conservation in human-modified Amazonian forest landscapes. Biological Conservation, n. 143, p. 2314-2327, 2010.

Pinhati, F. C. Geoprocessamento aplicado à avaliação de pastagens em terras Indígenas: o caso da Terra Indígena Badjônkôre. Revista de Estudos e Pesquisas, v. 2, n. 2, p. 145-170, 2005.

Ponzoni, F. J. \& Shimabukuro Y. E. Sensoriamento remoto no estudo da vegetação. São José dos Campos: Parêntese, 2007.

Ponzoni, F. J. \& Shimabukuro, Y. E. Sensoriamento remoto no estudo da vegetação. São José dos Campos: Parêntese, 2009.

Projeto diagnóstico e ordenamento ambiental das terras indígenas da Amazônia Legal. Prodial. Sub-projeto Alto Rio Guamá. Brasília, DF: Funai/Sudam, 2000.115 p. Relatório final.

Rouse, J. W. et al. Monitoring vegetation systems in the Great Plains with ERTS. In: EARTH RESOURCES TECHNOLOGY SATELLITE SYMPOSIUM, 3., 1973, Washington. Proceedings. Washington: NASA, 1974. p. 309-317.

Sales, N. P. Pressão e resistência: os índios Tembé-Tenetehara do Alto Rio Guamá e a relação com território. Belém, UNAMA, 1999. $89 \mathrm{p}$. 
Salles, A. T et al. Monitoramento da cobertura vegetal nas reservas indígenas Guarani/Kaiowá, através de técnicas de sensoriamento remoto e geoprocessamento. In: SIMPÓSIO BRASILEIRO DE SENSORIAMENTO REMOTO, IX, 1998, Santos. Anais... Santos: INPE, 1998. p.189-200.

Santos Junior, V. J. dos \& Fernandes, F. H. S. Uso do geoprocessamento no monitoramento da cobertura vegetal da Terra Indígena dos Xakriabá, no Norte do estado de Minas Gerais. Anais..., 2014. Rio de Janeiro.Porto Alegre: Editora Letra1; Rio de Janeiro: REBRAGEO, 2014, p. 484-493.

Silva Neto, B. Perda da vegetação natural na Chapada do Araripe (1975/2007) no estado do Ceará. 2013. 186 f. Tese (Doutorado em Geografia) - Universidade Estadual Paulista, Rio Claro, SP.

Soares Filho, B. et al. Role of Brazilian Amazon protected areas in climate change mitigation. Proceedings of the National Academy of Sciences of the United States of America, v. 107, n. 24, p. 1-6, 2010. DOI: 10.1073/pnas.0913048107.
Soares, S. C. \& Mota, A. L. T. S. da. Diminuição das florestas naturais no mundo. In: CONGRESSO NACIONAL DE EXCELÊNCIA EM GESTÃO, 6., 2010, Niterói. Anais... Rio de Janeiro, 2010.

Tundisi, J. G. \& Matsumura-Tundisi, T. M. Impactos potenciais das alterações do Código Florestal nos recursos hídricos. Biota Neotropical, v. 10, n. 4, p. 67-76, 2010.

United States Geological Survey. Disponível em: < https://www. usgs.gov/>. Acesso em: 11 jul. 2018.

Vieira, C. H. N. et al. Spatial and temporal land use and land cover of the Upper Jardim River Basin, Distrito Federal, Brazil. Revista Brasileira de Geografia Física, v. 11, n. 1, p. 85-98, 2018. 